\title{
Dysphagia in the elderly: management and nutritional considerations
}

This article was published in the following Dove Press journal:

Clinical Interventions in Aging

27 July 2012

Number of times this article has been viewed

\author{
Livia Sura ${ }^{1,2}$ \\ Aarthi Madhavan ${ }^{1,3}$ \\ Giselle Carnaby ${ }^{1,4}$ \\ Michael A Crary ${ }^{1,3}$ \\ 'Swallowing Research Laboratory; \\ 2Department of Epidemiology, \\ College of Public Health and Health \\ Professions; ${ }^{3}$ Department of Speech, \\ Language, and Hearing Sciences, \\ College of Public Health and \\ Health Professions; ${ }^{4}$ Department \\ of Behavioral Sciences and \\ Community Health, College \\ of Public Health and Health \\ Professions, Gainesville, FL, USA
}

\begin{abstract}
Dysphagia is a prevalent difficulty among aging adults. Though increasing age facilitates subtle physiologic changes in swallow function, age-related diseases are significant factors in the presence and severity of dysphagia. Among elderly diseases and health complications, stroke and dementia reflect high rates of dysphagia. In both conditions, dysphagia is associated with nutritional deficits and increased risk of pneumonia. Recent efforts have suggested that elderly community dwellers are also at risk for dysphagia and associated deficits in nutritional status and increased pneumonia risk. Swallowing rehabilitation is an effective approach to increase safe oral intake in these populations and recent research has demonstrated extended benefits related to improved nutritional status and reduced pneumonia rates. In this manuscript, we review data describing age related changes in swallowing and discuss the relationship of dysphagia in patients following stroke, those with dementia, and in community dwelling elderly. Subsequently, we review basic approaches to dysphagia intervention including both compensatory and rehabilitative approaches. We conclude with a discussion on the positive impact of swallowing rehabilitation on malnutrition and pneumonia in elderly who either present with dysphagia or are at risk for dysphagia.
\end{abstract}

Keywords: dysphagia, aging, malnutrition, pneumonia, rehabilitation

\section{Introduction}

Dysphagia (swallowing difficulty) is a growing health concern in our aging population. Age-related changes in swallowing physiology as well as age-related diseases are predisposing factors for dysphagia in the elderly. In the US, dysphagia affects 300,000-600,000 persons yearly. ${ }^{1}$ Although the exact prevalence of dysphagia across different settings is unclear, conservative estimates suggest that $15 \%$ of the elderly population is affected by dysphagia. ${ }^{2}$ Furthermore, according to a single study, dysphagia referral rates among the elderly in a single tertiary teaching hospital increased $20 \%$ from 2002-2007; with 70\% of referrals for persons above the age of $60 .{ }^{3}$ The US Census Bureau indicates that in 2010, the population of persons above the age of 65 was 40 million. Taken together, this suggests that up to 6 million older adults could be considered at risk for dysphagia.

Any disruption in the swallowing process may be defined as dysphagia. ${ }^{4}$ Persons with anatomical or physiologic deficits in the mouth, pharynx, larynx, and esophagus may demonstrate signs and symptoms of dysphagia. ${ }^{4}$ In addition, dysphagia contributes to a variety of negative health status changes; most notably, increased risk of malnutrition and pneumonia. In this review, we will discuss how aging and disease impact swallowing physiology with a focus on nutritional status and pneumonia. We will
Correspondence: Michael A Crary Box 100174, UF Health Science Center, Gainesville, FL 32610-0174, USA

Tel +l 3522735299

Fax +I 3522737825

Email mcrary@phhp.ufl.edu 
conclude with a brief overview of dysphagia management approaches and consequences of dysphagia management on nutritional status and pneumonia in the elderly.

\section{Aging effects on swallow function}

Swallow physiology changes with advancing age. Reductions in muscle mass and connective tissue elasticity result in loss of strength ${ }^{5}$ and range of motion. ${ }^{6}$ These age-related changes can negatively impact the effective and efficient flow of swallowed materials through the upper aerodigestive tract. In general, a subtle slowing of swallow processes occurs with advancing age. Oral preparation of food requires more time and material transits through the mechanism more slowly. Over time, these subtle but cumulative changes can contribute to increased frequency of swallowed material penetrating into the upper airway and greater post-swallow residue during meals. ${ }^{6}$ Beyond subtle motor changes, age-related decrements in oral moisture, taste, and smell acuity may contribute to reduced swallowing performance in the elderly. Though sensorimotor changes related to healthy aging may contribute to voluntary alterations in dietary intake, the presence of age-related disease is the primary factor contributing to clinically significant dysphagia in the elderly.

\section{Dysphagia and its sequelae}

Disease risk increases with advancing age. Due to the complexity of the swallowing process, many adverse health conditions can influence swallowing function. Neurological diseases, cancers of the head/neck and esophagus, and metabolic deficits are broad categories of diseases that might contribute to dysphagia. Table 1 summarizes different categories of diseases and health conditions that negatively impact functional swallowing ability.

Dysphagia affects up to $68 \%$ of elderly nursing home residents, ${ }^{7}$ up to $30 \%$ of elderly admitted to the hospital, ${ }^{8}$ up to $64 \%$ of patients after stroke, ${ }^{9,10}$ and $13 \%-38 \%$ of elderly who live independently. ${ }^{11-13}$ Furthermore, dysphagia has been associated with increased mortality and morbidity. ${ }^{14}$ Two prevalent diseases of aging are stroke and dementia. In 2005, $2.6 \%$ of all noninstitutionalized adults (over 5 million people) in the US reported that they had previously experienced a stroke. ${ }^{15}$ The prevalence of stroke also increases with age, with $8.1 \%$ of people older than 65 years reporting having a stroke. $^{15}$

Similarly, adults older than 65 years demonstrate an increased prevalence of dementia, with estimates between $6 \%-14 \%{ }^{16,17}$ Prevalence of dementia increases to over $30 \%$ beyond 85 years of age, ${ }^{16}$ and over $37 \%$ beyond 90 years. ${ }^{17}$
Table I Conditions that may contribute to dysphagia ${ }^{4}$

\author{
Neurologic disease \\ Stroke \\ Dementia \\ Traumatic brain injury \\ Myasthenia gravis \\ Cerebral palsy \\ Guillain-Barré syndrome \\ Poliomyelitis \\ Myopathy \\ Progressive disease \\ Parkinson's disease \\ Huntington disease \\ Age-related changes \\ Rheumatoid disease \\ Polydermatomyositis \\ Progressive systemic sclerosis \\ Sjögren disease \\ Other \\ Any tumor involving the aerodigestive tract \\ latrogenic diagnoses \\ Radiation therapy \\ Chemotherapy \\ Intubation tracheostomy \\ Medication related \\ Other, related diagnoses \\ Severe respiratory compromise \\ Adapted from Groher ME, Crary MA. Dysphagia: Clinical Management in adults and \\ children. Maryland Heights, MO: Mosby Elsevier; 2010.
}

Common complications of dysphagia in both stroke and dementia include malnutrition and pneumonia.

\section{Dysphagia and nutrition in stroke}

Dysphagia is highly prevalent following stroke with estimates ranging 30\%-65\%. ${ }^{9,10,18,19}$ Specific to the US, the Agency for Healthcare Research and Quality estimates that about 300,000-600,000 persons experience dysphagia as a result of stroke or other neurological deficits. ${ }^{20}$ Although many patients regain functional swallowing spontaneously within the first month following stroke,$^{10}$ some patients maintain difficulty swallowing beyond 6 months. ${ }^{9,21}$ Complications that have been associated with dysphagia post-stroke include pneumonia, ${ }^{22,23}$ malnutrition, ${ }^{24}$ dehydration, ${ }^{10,24}$ poorer long-term outcome, ${ }^{10,21}$ increased length of hospital stay, ${ }^{25}$ increased rehabilitation time and the need for long-term care assistance, ${ }^{26}$ increased mortality, ${ }^{10,19,22}$ and increased health care costs..$^{10}$ These complications impact the physical and social well being of patients, quality of life of both patients and caregivers, and the utilization of health care resources. ${ }^{20}$

In the acute phase of stroke, between $40 \%-60 \%$ of patients are reported to have swallowing difficulties. ${ }^{9,10}$ 
These difficulties may contribute to malnutrition due to limited food and liquid intake. Decreased food and liquid intake may reflect altered level of consciousness, physical weakness, or incoordination in the swallowing mechanism. ${ }^{27}$ Although the odds of malnutrition are increased in the presence of dysphagia following stroke, ${ }^{28}$ pre-stroke factors should be considered when assessing nutritional status and predicting stroke outcome. For example, upon admission, approximately $16 \%$ of stroke patients present with nutritional deficits. During acute hospitalization, nutritional deficits may worsen with reported prevalence increasing to $22 \%-26 \%$ at discharge from acute care. ${ }^{29-31}$ Although nutritional deficits and dysphagia often coexist, malnutrition does not appear to be associated with dysphagia in the acute phase of stroke..$^{32}$ Rather, malnutrition is more prevalent during the post acute rehabilitation phase, with a reported prevalence of up to $45 \%{ }^{33}$ Reduced food/liquid intake during acute hospitalization associated with dysphagia may be a contributing factor to increased malnutrition rates during subsequent rehabilitation. $^{28}$

\section{Dysphagia and pneumonia in stroke}

Post-stroke pneumonia is a common adverse infection that affects up to one-third of acute stroke patients..$^{34,35}$ Pneumonia is also a leading cause of mortality after stroke, accounting for nearly $35 \%$ of post-stroke deaths. ${ }^{36}$ Most stroke-related pneumonias are believed to result from dysphagia and the subsequent aspiration of oropharyngeal material. Aspiration is defined as entry of food or liquid into the airway below the level of the true vocal cords, ${ }^{37}$ and aspiration pneumonia is defined as entrance of swallowed materials into the airway that results in lung infection. ${ }^{4}$ A recent systematic review reported that stroke patients with dysphagia demonstrate $\geq 3$-fold increase in pneumonia risk with an 11-fold increase in pneumonia risk among patients with confirmed aspiration..$^{22}$ Along with this increased risk, the burden of aspiration pneumonia is high. Increased costs associated with longer hospitalization, ${ }^{10}$ greater disability at 3 and 6 months, ${ }^{10,38}$ and poor nutritional status during hospitalization ${ }^{10}$ characterize aspiration pneumonia in stroke.

\section{Dysphagia and dementia}

Dysphagia is a common symptom in dementia. It has been estimated that up to $45 \%$ of patients institutionalized with dementia have some degree of swallowing difficulty. ${ }^{39}$ Different clinical presentations of dementia will result in different swallowing or feeding impairments. ${ }^{40-43}$ Most commonly, patients with dementia demonstrate a slowing of the swallowing process. ${ }^{14}$ Slowed swallow processes may increase time taken to finish a meal and subsequently increase the risk for poor nutritional status. ${ }^{14}$ Furthermore, patients with dementia often have difficulties self-feeding. These difficulties may relate to cognitive impairment, motor deficits such as weakness or apraxia, loss of appetite, and/ or food avoidance. As a result, patients with dementia may experience weight loss and increased dependency for feeding. ${ }^{14}$ Subsequently, increased feeding dependency may lead to other dysphagia-related health problems, including pneumonia. ${ }^{14}$ Weight loss can reflect decreased nutritional status which increases the patient's risk of opportunistic infections such as pneumonia. ${ }^{44-46}$ Pneumonia is a common cause of mortality in patients with dementia. ${ }^{47}$ Thus, dementia, dysphagia, and related feeding impairments can lead to nutritional deficits which in turn contribute to pneumonia and mortality. Among elderly patients in particular, the presence of dementia is associated with higher hospital admission rates and overall higher mortality. ${ }^{48}$ Moreover, elderly patients admitted to a hospital with dementia have a higher overall prevalence of both pneumonia and stroke, suggesting that aging significantly increases the risk for these negative health states. ${ }^{48}$

\section{Dysphagia and nutrition in community dwelling elderly adults}

Dysphagia can result in reduced or altered oral intake of food/ liquid which, in turn, can contribute to lowered nutritional status. One group which merits more attention in reference to potential relationships between dysphagia and nutritional status is community dwelling elderly adults. Dysphagia can contribute to malnutrition, and malnutrition can further contribute to decreased functional capacity. Thus, dysphagia may trigger or promote the frailty process among elderly persons. ${ }^{46}$

In a group of 65-94-year-old community dwelling adults, prevalence of dysphagia was reported to be $37.6 \% .^{13}$ Of these, $5.2 \%$ reported the use of a feeding tube at some point in life, and $12.9 \%$ reported the use of nutritional supplements to reach an adequate daily caloric intake. ${ }^{13}$ In another cohort of independently living older persons, prevalent cases of malnutrition or those at risk for malnutrition were estimated at $18.6 \%$ of elderly adults with dysphagia, and $12.3 \%$ of adults without dysphagia. Significant differences in nutritional status were noted between these subgroups at 1-year follow-up. ${ }^{46}$ These figures underscore the prevalence and importance of malnutrition and dysphagia among elderly individuals. Moreover, they suggest that dysphagic elderly 
living in the community are likely to present with an elevated risk of malnutrition.

\section{Dysphagia and pneumonia in community dwelling elderly adults}

The prevalence of community-acquired pneumonia in elderly adults is rising, with a greater risk of infection in those older than 75 years. ${ }^{49-51}$ In addition, deaths from pneumonitis due to aspiration of solids and liquids (eg, aspiration pneumonia) are increasing and are currently ranked 15 th on the CDC list of common causes of mortality. ${ }^{52}$ Frequency of pneumonia and its associated mortality increases with advancing age. ${ }^{53}$ More specifically, the prevalence of pneumonia in community dwelling persons increases in a direct relationship to aging and the presence of disease. ${ }^{45}$ Furthermore, an increased prevalence of dysphagia in the elderly increases the risk for pneumonia. $^{54}$

It appears that with the aging population, both dysphagia and pneumonia rates are increasing. However, relationships between dysphagia and pneumonia in community dwelling elderly are poorly understood. Cabre and colleagues reported that $55 \%$ of 134 community dwelling elderly adults 70 years and older diagnosed with pneumonia upon admission to a geriatric hospital unit, presented with clinical signs of oropharyngeal dysphagia. ${ }^{55}$ In this cohort, cases presenting with dysphagia were older, presented with more severe pneumonia, greater decline in functional status, and demonstrated a higher prevalence of malnutrition. ${ }^{55}$ These patients also demonstrated increased mortality at 30 days and 1-year follow-up. ${ }^{55}$ Also, a recent study evaluated relationships between oropharyngeal dysphagia and the risk for malnutrition and lower respiratory tract infectionscommunity-acquired pneumonia (LRTI-CAP) in a cohort of independently living older persons. Results indicated that $40 \%$ of LRTI-CAP cases presented with dysphagia, compared to $21.8 \%$ who did not present with dysphagia. ${ }^{46}$ These findings highlight the potential relationships among dysphagia, nutritional status, and pneumonia in community dwelling elderly.

\section{Dysphagia management}

The presence of a strong relationship between swallowing ability, nutritional status, and health outcomes in the elderly suggests a role for dysphagia management in this population. Successful swallowing interventions not only benefit individuals with reference to oral intake of food/liquid, but also have extended benefit to nutritional status and prevention of related morbidities such as pneumonia. A variety of dysphagia management tools are available pending the characteristics of the swallowing impairment and the individual patient.

\section{Swallowing management}

Dysphagia management is a 'team event'. Many professionals may contribute to the management of dysphagia symptoms in a given patient. Furthermore, no single strategy is appropriate for all elderly patients with dysphagia. Concerning behavioral management and therapy, speech-language pathologists (SLP) play a central role in the management of patients with dysphagia and related morbidities. SLP clinical assessment is often supplemented with imaging studies (endoscopy and/or fluoroscopy), and these professionals may engage in a wide range of interventions. Some intervention strategies, termed 'compensations', are intended to be utilized for short periods in patients who are anticipated to improve. Compensations are viewed as short-term adjustments to the patient, food and/or liquid, or environment, with the goal of maintaining nutrition and hydration needs until the patient can do so by themselves. Other patients require more direct, intense rehabilitation strategies to improve impaired swallow functions. A brief review of each general strategy with examples follows.

\section{Compensatory management}

Compensatory strategies focus on implementation of techniques to facilitate continued safe oral intake of food and/or liquid; or to provide alternate sources of nutrition for maintenance of nutritional needs. Compensatory strategies are intended to have an immediate benefit on functional swallowing through simple adjustments that allow patients to continue oral diets safely. Compensatory strategies include, but are not limited to, postural adjustments of the patient, swallow maneuvers, and diet modifications (foods and/or liquids). ${ }^{14}$

\section{Postural adjustments}

Changes in body and/or head posture may be recommended as compensatory techniques to reduce aspiration or residue. ${ }^{56}$ Changes in posture may alter the speed and flow direction of a food or liquid bolus, often with the intent of protecting the airway to facilitate a safe swallow. ${ }^{14}$ Table 2 lists commonly used postural adjustments. In general, these postural adjustments are intended to be utilized short term, and the impact of each may be evaluated during the clinical examination or with imaging studies. Available literature on the benefit of these techniques is variable. For example, while some investigators report reduced aspiration from a chin 
Table 2 Examples of postural adjustments

\begin{tabular}{|c|c|c|c|}
\hline Technique & Performance & Intended outcome & Reported benefit \\
\hline \multicolumn{4}{|l|}{ Body posture changes } \\
\hline Lying down & $\begin{array}{l}\text { - Lie down/angled } \\
\text { - Reduce impact of gravity during swallow }\end{array}$ & $\begin{array}{l}\text { - Increased hypopharyngeal } \\
\text { pressure on bolus }\end{array}$ & - Increased PES opening ${ }^{60}$ \\
\hline Side lying & - Lie down on stronger side (lower) & $\begin{array}{l}\text { - Slows bolus } \\
\text { - Provides time to adjust/protect airway }\end{array}$ & - Less aspiration ${ }^{56}$ \\
\hline \multicolumn{4}{|l|}{ Head posture changes } \\
\hline Head extension/chin up & - Raise chin & $\begin{array}{l}\text { - Propels bolus to back of mouth } \\
\text { - Widens oropharynx }\end{array}$ & $\begin{array}{l}\text { - Reduced aspiration } \\
\text { - Better bolus transport }\end{array}$ \\
\hline Head flexion/chin tuck & - Tucking chin towards the chest & - Improves airway protection & - Reduced aspiration ${ }^{56,57,61}$ \\
\hline Head rotation/head turn & - Turning head towards the weaker side & $\begin{array}{l}\text { - Reduces residue after swallow } \\
\text { - Reduces aspiration }\end{array}$ & $\begin{array}{l}\text { - Less residue }{ }^{62} \\
\text { - Reduced aspiration }{ }^{56}\end{array}$ \\
\hline
\end{tabular}

down technique, ${ }^{56,57}$ others report no significant benefit ${ }^{58}$ or no superior benefit to other compensations like thick liquids. ${ }^{57}$ Furthermore, these compensatory strategies only impact nutritional status or pneumonia when they allow patients to consume adequate amounts of food/liquid in the absence of airway compromise leading to chest infection. No existing data confirms this potential benefit of postural adjustments and some data suggest that these strategies are inferior to more active rehabilitation efforts in the prevention of nutritional deficits and pneumonia. ${ }^{59}$

\section{Swallow maneuvers}

Swallow maneuvers are 'abnormal' variants on the normal swallow intended to improve the safety or efficiency of swallow function. Various swallow maneuvers have been suggested to address different physiologic swallowing deficits. ${ }^{14}$ Table 3 presents commonly used swallow maneuvers. Swallow maneuvers can be used as short-term compensations but many have also been used as swallow rehabilitative strategies. Different maneuvers are intended to address different aspects of the impaired swallow. For example, the supraglottic and super supraglottic swallow techniques both incorporate a voluntary breath hold and related laryngeal closure to protect the airway during swallowing. ${ }^{14}$ The Mendelsohn maneuver is intended to extend opening or more appropriately relaxation of the upper esophageal sphincter. ${ }^{63}$ Finally, the effortful or 'hard' swallow is intended to increase swallow forces on bolus materials with the result of less residue or airway compromise. ${ }^{64,65}$ Like postural adjustments, available data on the success of these techniques in patient populations is limited, conflicted, and often comprised of small samples. ${ }^{59,66-68}$ Thus, the best advice for clinicians is to verify the impact of these maneuvers using swallowing imaging studies before introducing any of them as compensatory strategies. Also, similar to postural adjustments, no significant research has demonstrated the impact of these maneuvers, when used as compensatory strategies, on nutritional status or pneumonia.

\section{Diet modifications: modification of foods/liquids}

Modifying the consistency of solid food and/or liquid is a mainstay of compensatory intervention for patients with dysphagia. ${ }^{37}$ The goal of diet modification is to improve the safety and/or ease of oral consumption and thus maintain safe and adequate oral intake of food/liquid. However, low acceptability and resulting poor adherence with modified foods/liquids can contribute to increased risk of inadequate nutrition in elderly patients with dysphagia.

\section{Thickened liquids}

The use of thickened liquids is 'one of the most frequently used compensatory interventions in hospitals and long-term

Table 3 Examples of swallow maneuvers

\begin{tabular}{|c|c|c|c|}
\hline Swallow maneuver & Performance & Intended outcome & Reported benefit \\
\hline Supraglottic swallow & $\begin{array}{l}\text { Hold breath, swallow, } \\
\text { and then gentle cough }\end{array}$ & $\begin{array}{l}\text { - Reduce aspiration and increase } \\
\text { movement of the larynx }\end{array}$ & - Reduces aspiration ${ }^{66}$ \\
\hline Super supraglottic swallow & $\begin{array}{l}\text { - Hold breath, bear down, } \\
\text { swallow, and then gentle cough }\end{array}$ & & \\
\hline $\begin{array}{l}\text { Effortful swallow. Also called } \\
\text { 'hard' or 'forceful' swallow }\end{array}$ & - Swallow 'harder' & $\begin{array}{l}\text { - Increased lingual force on the bolus } \\
\text { - Less aspiration and pharyngeal residue }\end{array}$ & $\begin{array}{l}\text { - Increased pharyngeal pressure } \\
\text { and less residue } 67,68\end{array}$ \\
\hline Mendelsohn maneuver & - 'Squeeze' swallow at apex & - Improve swallow coordination & - Reduced residue and aspiration ${ }^{69}$ \\
\hline
\end{tabular}


care facilities'. ${ }^{70}$ Generally accepted clinical intuition and anecdotal evidence claim that thickened liquids have an effect in helping to control the speed, direction, duration, and clearance of the bolus. ${ }^{70}$ However, only scant evidence suggests that thickened liquids result in significant positive health outcomes with regards to nutritional status or pneumonia. Despite the overall lack of evidence supporting the use of thickened liquids, this strategy continues to be a cornerstone in dysphagia management in many facilities. ${ }^{70}$ For example, a survey of 145 SLPs by Garcia et al reported that $84.8 \%$ of the respondents felt that thickening liquids was an effective management strategy for swallowing disorders with nectar thick liquids being the most frequently used. ${ }^{71}$ Unfortunately, the perceptions of these clinicians are not supported by available research. For example, Logemann et $\mathrm{al}^{57}$ reported that honey thick liquid was more effective in reducing aspiration during fluoroscopic swallow examination than nectar thick liquids (or the chin down technique). But, even this benefit disappeared when honey thick liquids were administered at the end of the examination. Kuhlemeier et $\mathrm{al}^{72}$ identified 'ultrathick' liquid to have lower aspiration rates than thick or thin liquids, although the manner of presentation (cup vs spoon) modified their results. Thus, available evidence appears discrepant from clinician perceptions regarding use of thick liquids. Beyond this scenario, thick liquids may present pragmatic limitations in clinical practice.

\section{Limitations of thickened liquids}

A primary concern with the overuse of thickened liquids is the risk of dehydration in elderly patients with dysphagia. Patient compliance with thickened liquids is often reduced. ${ }^{4}$ A recent survey of SLPs suggested that honey thick liquids were strongly disliked by their patients but even nectar thick liquids were poorly accepted by more than one in ten patients. ${ }^{71}$ Poor compliance with thickened liquids may lead to reduced fluid intake and an increased risk of dehydration. ${ }^{73}$ Beyond patient acceptance, no strong evidence is available supporting the use of thickened liquids as an intervention for patients with dysphagia. Only a single randomized trial has compared treatment outcomes between the chin down technique and nectar or honey thick liquids in patients with dysphagia. ${ }^{74}$ The results of this study revealed no significant differences between these strategies on the primary outcome of pneumonia. Consequently, strong evidence for the preferential use of liquid thickening as a strategy in dysphagia intervention is not currently available.
An alternative approach to thickened liquids has been recommended to counter the risk for dehydration due to reduced fluid intake and dislike for thickened liquids. This approach, the 'Frazier water protocol', utilizes specific water intake guidelines and allows patients with dysphagia to consume water between meals. ${ }^{75}$ Although this technique has not yet been objectively assessed, experiences from the Frazier Rehabilitation Institute are impressive. Results suggest low rates of dehydration $(2.1 \%)$ and chest infection $(0.9 \%)$ in 234 elderly patients. With additional confirming results, this approach may become more widely used as a dysphagia intervention.

\section{Modified food diets}

Solid foods may be modified to accommodate perceived limitations in elderly patients with dysphagia. Solid food modification has been suggested to promote safe swallowing and adequate nutrition. However, no strong and universal clinical guidelines are available to describe the most appropriate modification of foods. ${ }^{14}$ At least one study indicated that among nursing home residents, $91 \%$ of patients placed on modified diets were placed on overly restrictive diets. ${ }^{76}$ Only $5 \%$ of these patients were identified to be on an appropriate diet level matching their swallow ability and $4 \%$ of patients were placed on diets above their clinically measured swallow ability. More recently, in an attempt to standardize the application of modified diets in patients with dysphagia, the National Dysphagia Diet was proposed. ${ }^{77}$ The National Dysphagia Diet is comprised of four levels of food modification with specific food items recommended at each level (Table 4). While this approach is commendable, unfortunately, to date no studies have compared the benefit of using this standardized approach to institution specific diet modification strategies.

\section{Limitations of modified solids}

Although recommended to promote safe swallowing and reduce aspiration in patients with dysphagia, modified diets may result in reduced food intake, increasing the risk of malnutrition for some patients with dysphagia. ${ }^{78}$ Available literature on the nutritional benefit of modified diets is conflicted. ${ }^{79,80}$ One study evaluated dietary intake over the course of a day in hospitalized patients older than 60 years. The authors compared intake in patients consuming a regular diet to those consuming a texture modified diet and found that patients on the modified diet had a significantly lower nutritional intake in terms of energy and protein. Additionally, $54 \%$ of patients on a texture modified diet were recommended 
Table 4 Levels of modified $\operatorname{diet}^{77}$

\begin{tabular}{|c|c|c|}
\hline Level & Description & Examples of recommended foods \\
\hline \multicolumn{3}{|c|}{ Four Levels in the National dysphagia diet } \\
\hline \multirow[t]{5}{*}{ Level I: dysphagia pureed } & Homogeneous, cohesive, and pudding like. & Smooth, homogenous cooked cereals \\
\hline & No chewing required, only bolus control & Pureed: meats, starches (like mashed potatoes), \\
\hline & & and vegetables with smooth sauces without lumps \\
\hline & & Pureed/strained soups \\
\hline & & Pudding, soufflé, yogurt \\
\hline \multirow[t]{3}{*}{ Level 2: dysphagia mechanically altered } & Moist, semi-solid foods, cohesive. & Cooked cereals with little texture \\
\hline & Requires chewing ability & Moistened ground or cooked meat \\
\hline & & Moistened, soft, easy to chew canned fruit and vegetables \\
\hline \multirow[t]{3}{*}{ Level 3: dysphagia advanced } & Soft-solids. Require more chewing ability & Well moistened breads, rice, and other starches \\
\hline & & Canned or cooked fruit and vegetables \\
\hline & & Thin sliced, tender meats/poultry \\
\hline Level 4: regular & No modifications, all foods allowed & No restrictions \\
\hline
\end{tabular}

Adapted from Groher ME, Crary MA. Dysphagia: Clinical management in adults and children. Maryland Heights, MO. Mosby, Elsevier; 2010.

a nutritional supplement, compared with $24 \%$ of patients on a regular diet. ${ }^{79}$ Conversely, Germain et al ${ }^{80}$ compared patients consuming a modified diet with greater food choices to patients consuming a 'standard' (more restricted) modified diet over a 12 -week period. They found significantly greater nutritional intake in patients consuming the expanded option diet. Additionally, they observed a significant weight gain in the patients consuming the expanded option diet at the end of 12 weeks.

\section{Feeding dependence and targeted feeding}

As mentioned previously, elderly patients with dementia and stroke may be dependent on others for feeding due to cognitive and/or physical limitations. Feeding dependence poses an increased risk for aspiration and related complications in patients with dysphagia due to factors such as rapid and uncontrolled presentation of food by feeders. ${ }^{81}$ This finding poses serious concern for patients with dysphagia on long-term modified diets. Implementing targeted feeding training can compensate for these difficulties and reduce related complications. For example, oral intake by targeted feeding (by trained individuals) in patients with dysphagia resulted in higher energy and protein intake compared to a control condition where no feeding assistance was provided. ${ }^{78}$

In combination with specific training on feeding, other strategies to monitor rate and intake of food may help increase safety, decrease fatigue, and improve feedback on successful swallowing for the patients during the course of the meal. ${ }^{37}$ Eating in environments without external distractions, especially in skilled nursing or long-term care settings, are essential to this aim. Likewise, the prescription and provision of adaptive equipment like cups without rims and angled utensils, etc, may also support improved outcomes for elderly dysphagic patients. ${ }^{37}$

\section{Provision of alternate nutrition}

Perhaps the ultimate form of compensation would be the use of alternate nutrition strategies. Non-oral feeding sources can benefit patients with nutritional deficits. This is especially true in the elderly, as malnutrition contributes to a variety of health problems including cardiovascular disease, deterioration of cognitive status and immune system, and poorly healing pressure ulcers and wounds. ${ }^{82,83}$ Patient populations most commonly receiving non-oral feeding support include the general category of dysphagia (64.1\%), and patients with stroke $(65.1 \%)^{84}$ or dementia $(30 \%){ }^{85}$

While non-oral feeding methods provide direct benefit in many clinical situations, they do not benefit all elderly patients with dysphagia or nutritional decline. For example, regarding enteral feeding in patients with advanced dementia, Finucane et $\mathrm{al}^{86}$ did not find strong evidence to suggest that non-oral feeding prevented aspiration pneumonia, prolonged survival, improved wound healing, or reduced infections. Moreover, a study of $>80,000$ Medicare beneficiaries over the age of 65 years indicated that presence of a percutaneous endoscopic gastrostomy (PEG) tube in hospitalized patients had a high mortality rate $(23.1 \%)$. Mortality increased to $63 \%$ in 1 year. ${ }^{87}$ In addition, adverse events associated with non-oral feeding sources are common and include local wound complications, leakage around the insertion site, tube occlusion, and increased reflux leading to other complications such as pneumonia. Finally, the presence of alternate feeding methods can also promote a cascade of negative psychosocial features including depression and loss of social interaction associated with feeding. ${ }^{86,88}$ Despite the 
associated complications and impacts of non-oral feeding, provision of alternate feeding has demonstrated impact on nutritional adequacy and weight maintenance in some elderly populations and is therefore an important option in dysphagia management. ${ }^{37}$

\section{Swallow rehabilitation}

The focus of swallow rehabilitation is to improve physiology of the impaired swallow. As such, many swallow rehabilitation approaches incorporate some form of exercise. ${ }^{4}$ Though the focus and amount of exercise varies widely from one rehabilitation approach to another, in general, exercise-based swallowing interventions have been shown to improve functional swallowing, minimize or prevent dysphagia-related morbidities, and improve impaired swallowing physiology. ${ }^{59,89-92}$ Table 5 presents examples of recent exercise-based approaches to swallow rehabilitation. Though each of these programs differs in focus and technique, each shares some commonalities. Specifically, each incorporates some component of resistance into the exercise program and each advocates an intensive therapy program monitored by the amount of work completed by patients. Some are specific to comprehensive swallow function, while others focus on strengthening individual swallow subsystems. Yet, each program is novel and shares the common goal of improving impaired swallowing physiology.

Perhaps one of the more traditional approaches to swallow rehabilitation is the use of oral motor exercises. Although, there is limited information on the effectiveness of oral motor exercises, recent studies have shown effective strengthening of swallow musculature and hence improved swallowing with the use of lip and tongue resistance exercises. ${ }^{89,93,94}$
More recent exercise approaches such as expiratory muscle strength training (EMST) or the Shaker head lift exercise focus on the use of resistance to strengthen swallowing subsystems. As implied by the name, EMST attempts to strengthen the respiratory muscles of expiration. However, initial research has indicated potential extended benefits to swallow function. For example, EMST has been shown to increase hyolaryngeal movement and improve airway protection in patients with Parkinson's disease. ${ }^{95}$ As indicated in the name, the head lift exercise developed by Shaker incorporates both repetitive and sustained head raises from a lying position. ${ }^{96}$ Improvements from this exercise include increased anterior laryngeal excursion and upper esophageal sphincter opening during swallowing, both of which contribute to more functional swallowing ability. These positive physiologic changes have been demonstrated in healthy older adults and also in patients on tube feeding due to abnormal upper esophageal sphincter opening. ${ }^{96,97}$

The McNeill Dysphagia Therapy Program (MDTP) is an exercise-based therapy program, using swallowing as an exercise. ${ }^{91}$ From this perspective, MDTP addresses the entire swallow mechanism, not just subsystems as in other approaches. This program is completed in daily sessions for 3 weeks and reports excellent functional improvement in patients with chronic dysphagia. In addition, recent studies have documented physiological improvements in strength, movement, and timing of the swallow. ${ }^{91,92}$

In addition to exercise-based interventions, the use of adjunctive modalities may be useful in swallowing rehabilitation. Application of adjunctive electrical stimulation has been widely debated and studied primarily in small samples. The rationale behind the application of electrical

Table 5 Examples of exercise-based swallow rehabilitation approaches

\begin{tabular}{|c|c|c|c|}
\hline Program & Focus & Intended outcome & Reported benefit \\
\hline Lingual resistance & $\begin{array}{l}\text { - Strengthening tongue with } \\
\text { progressively increasing intensity }\end{array}$ & $\begin{array}{l}\text { - Increased tongue strength } \\
\text { - Improved swallow }\end{array}$ & $\begin{array}{l}\text { - Increased tongue muscle mass } \\
\text { - Increased swallow pressure } \\
\text { - Reduced aspiration }{ }^{76}\end{array}$ \\
\hline Shaker/head-lift & $\begin{array}{l}\text { - Strengthening suprahyoid muscles } \\
\text { - Improve elevation of larynx } \\
\text { - Increasing UES opening }\end{array}$ & $\begin{array}{l}\text { - Improve strength of muscles } \\
\text { for greater UES opening }\end{array}$ & $\begin{array}{l}\text { - Increased larynx elevation } \\
\text { - Increased UES opening } \\
\text { - Less post-swallow aspiration }\end{array}$ \\
\hline $\begin{array}{l}\text { EMST (expiratory } \\
\text { muscle strength } \\
\text { training) }\end{array}$ & $\begin{array}{l}\text { - Strengthening submental muscle } \\
\text { - Improve expiratory pressures } \\
\text { for better airway protection }\end{array}$ & $\begin{array}{l}\text { - Improve expiratory drive } \\
\text { - Reduce penetration } \\
\text { and aspiration }\end{array}$ & $\begin{array}{l}\text { - Better penetration-aspiration scores } \\
\text { in Parkinson's disease } \\
\text { - Increased maximum expiratory pressure } \\
\text { - Increased submental muscle electromyography } \\
\text { activity during swallowing }\end{array}$ \\
\hline $\begin{array}{l}\text { MDTP (McNeill } \\
\text { dysphagia therapy } \\
\text { program) }\end{array}$ & $\begin{array}{l}\text { - Swallow as exercise with } \\
\text { progressive resistance }\end{array}$ & $\begin{array}{l}\text { - Improve swallowing including } \\
\text { strength and timing }\end{array}$ & $\begin{array}{l}\text { - Improved swallow strength } \\
\text { - Improved movement of swallow structures } \\
\text { - Improved timing } \\
\text { - Weight gain }{ }^{68,91,92}\end{array}$ \\
\hline
\end{tabular}

Abbreviations: UES, Upper Esophageal Sphincter. 
stimulation is that it facilitates increased muscle contraction during swallowing activity. Reported gains have included advances in oral diet, reduced aspiration, and reduced dependence on tube feeding. ${ }^{68,98,99}$ However, other studies have reported no significant differences in outcomes following dysphagia therapy with and without adjunctive neuromuscular electrical stimulation. ${ }^{100,101}$ Currently, the benefit of adding this modality to dyphagia therapy is not well documented; however, several smaller studies have suggested a clinical benefit. Surface electromyography (sEMG) has been demonstrated as a beneficial feedback mechanism in dysphagia rehabilitation.

sEMG biofeedback provides immediate information on neuromuscular activity associated with swallowing and is reported to help patients learn novel swallowing maneuvers quickly. Studies have documented that sEMG biofeedback facilitates favorable outcomes with reduced therapy time in patients, even with chronic dysphagia. ${ }^{102-104}$

\section{Impact of swallow rehabilitation on nutritional status and pneumonia}

As presented above, dysphagia, nutritional status, and pneumonia appear to have strong interrelationships in various elderly populations. Recent evidence suggests that successful swallowing rehabilitation and/or early preventative efforts may reduce the frequency of both malnutrition and pneumonia in elderly patients with dysphagia. For example, patients with dysphagia in acute stroke who received an intensive exercise-based swallow rehabilitation program demonstrated less malnutrition and pneumonia compared to patients receiving diet modifications and compensations or those receiving no intervention. ${ }^{59}$ Other studies have demonstrated improved functional oral intake following successful swallow rehabilitation measured by the Functional Oral Intake Scale (FOIS), removal of PEG tube, and/or improved nutritional markers. ${ }^{65,95-97}$ In the head and neck cancer population, recent clinical research has shown that exercise during the course of chemoradiation treatment helps preserve muscle mass with reduced negative nutritional outcomes common in this population..$^{90}$ Finally, one exercise-based swallow rehabilitation program (MDTP) has demonstrated positive nutritional outcomes in patients with chronic dysphagia, including weight gain, removal of feeding tubes, and increased oral intake. These benefits were maintained at a 3-month follow-up evaluation. ${ }^{91,92}$ Collectively, such research suggests that intensive swallow rehabilitation can result in improved nutritional status and a reduction of pneumonia in a variety of elderly populations with dysphagia.

\section{Summary}

A strong relationship appears to exist between dysphagia and the negative health outcomes of malnutrition and pneumonia in patients following stroke, those with dementia, and also in community dwelling elderly adults. This trilogy of deficits, prominent among the elderly, demands more efforts focused on early identification and effective rehabilitation and prevention. Addressing issues such as the most efficient and effective methods to identify dysphagia and malnutrition in high-risk patients and community dwelling elderly adults could result in reduced morbidity in elderly populations. Of particular interest are recent studies that implicate benefit from intensive swallowing rehabilitation in preventing nutritional decline and pneumonia in adults with dysphagia. Future research should extend this 'prophylactic' approach to other at-risk populations including community dwelling elderly adults.

\section{Disclosure}

The authors report no conflicts of interest in this work.

\section{References}

1. US Department of Health and Human Services. Agency for Healthcare Research and Quality. Diagnosis and treatment of swallowing disorders (dysphagia) in acute-care stroke patients. Evidence report/technology assessment (Summary). Archived EPC Evidence Reports. 1999:1-6.

2. Barczi SR, Sullivan PA, Robbins J. How should dysphagia care of older adults differ? Establishing optimal practice patterns. Semin Speech Lang. 2000;21:347-361.

3. Leder SB, Suiter DM. An epidemiologic study on aging and dysphagia in the acute care hospitalized population: 2000-2007. Gerontology. 2009;55:714-718.

4. Crary MA, Groher ME. Introduction to Adult Swallowing Disorders. Philadelphia, PA: Butterworth Heinemann; 2003.

5. Fucile S, Wright PM, Chan I, Yee S, Langlais ME, Gisel EG. Functional oralmotor skills: Do they change with age? Dysphagia. 1998;13:195-201.

6. Logemann JA, Stewart C, Hurd J, Aschman D, Matthews N. Diagnosis and Management of Dysphagia in Seniors. 2008. Available at: http://americandysphagianetwork.org/physician_education_course. Accessed February 24, 2012.

7. Steele CM, Greenwood C, Ens I, Robertson C, Seidman-Carlson R. Mealtime difficulties in a home for the aged: not just dysphagia. Dysphagia. 1997;12:43-50, discussion 51.

8. Lee A, Sitoh YY, Lieu PK, Phua SY, Chin JJ. Swallowing impairment and feeding dependency in the hospitalised elderly. Ann Acad Med Singapore. 1999;28:371-376.

9. Mann G, Hankey GJ, Cameron D. Swallowing function after stroke: prognosis and prognostic factors at 6 months. Stroke. 1999;30:744-748.

10. Smithard DG, O'Neill PA, Parks C, Morris J. Complications and outcome after acute stroke. Does dysphagia matter? Stroke. 1996;27:1200-1204.

11. Kawashima K, Motohashi Y, Fujishima I. Prevalence of dysphagia among community-dwelling elderly individuals as estimated using a questionnaire for dysphagia screening. Dysphagia. 2004;19:266-271. 
12. Serra-Prat M, Hinojosa G, López D, et al. Prevalence of oropharyngeal dysphagia and impaired safety and efficacy of swallow in independently living older persons. J Am Geriatr Soc. 2011;59:186-187.

13. Roy N, Stemple J, Merrill RM, Thomas L. Dysphagia in the elderly: preliminary evidence of prevalence, risk factors, and socioemotional effects. Ann Otol Rhinol Laryngol. 2007;116:858-865.

14. Groher ME, Crary MA. Dysphagia: Clinical Management in Adults and Children. Maryland Heights, MO: Mosby Elsevier; 2010.

15. MMWR Report. Prevalence of stroke- United States, 2005. MMWR Weekly. May 18, 2007;56(19):469-474. Available at: http://www.cdc. gov $/ \mathrm{mmwr} /$ preview/mmwrhtml/mm5619a2.htm. Accessed March 5, 2012.

16. Hendrie HC. Epidemiology of dementia and Alzheimer's disease. Am J Geriatr Psychiatry. 1998;6:S3-S18.

17. Plassman BL, Langa KM, Fisher GG, et al. Prevalence of dementia in the United States: the aging, demographics, and memory study. Neuroepidemiology. 2007;29:125-132.

18. Mann G, Hankey GJ, Cameron D. Swallowing disorders following acute stroke: prevalence and diagnostic accuracy. Cerebrovasc Dis. 2000;10:380-386.

19. Paciaroni M, Mazzotta G, Corea F, et al. Dysphagia following Stroke. Eur Neurol. 2004;51:162-167.

20. Carnaby-Mann G, Lenius K, Crary M. Update on Assessment and Management of Dysphagia Post Stroke. Northeast Florida Medicine. 2007;58:31-34.

21. Smithard DG, Smeeton NC, Wolfe CD. Long-term outcome after stroke: does dysphagia matter? Age Ageing. 2007;36:90-94.

22. Martino R, Foley N, Bhogal S, Diamant N, Speechley M, Teasell R. Dysphagia after stroke: incidence, diagnosis, and pulmonary complications. Stroke. 2005;36:2756-2763.

23. Martino R, Martin RE, Black S. Dysphagia after stroke and its management. CMAJ. 2011. [Epub ahead of print.]

24. Altman KW, Yu GP, Schaefer SD. Consequence of dysphagia in the hospitalized patient: impact on prognosis and hospital resources. Arch Otolaryngol Head Neck Surg. 2010;136:784-789.

25. Guyomard V, Fulcher RA, Redmayne O, Metcalf AK, Potter JF, Myint PK. Effect of dysphasia and dysphagia on inpatient mortality and hospital length of stay: a database study. $J$ Am Geriatr Soc. 2009;57:2101-2106.

26. Maeshima S, Osawa A, Miyazaki Y, et al. Influence of dysphagia on short-term outcome in patients with acute stroke. Am J Phys Med Rehabil. 2011;90:316-320.

27. Crary MA, Groher ME. Reinstituting oral feeding in tube-fed adult patients with dysphagia. Nutr Clin Pract. 2006;21:576-586.

28. Foley NC, Martin RE, Salter KL, Teasell RW. A review of the relationship between dysphagia and malnutrition following stroke. J Rehabil Med. 2009;41:707-713.

29. Axelsson K, Asplund K, Norberg A, Alafuzoff I. Nutritional status in patients with acute stroke. Acta Med Scand. 1988;224:217-224.

30. Davalos A, Ricart W, Gonzalez-Huix F, et al. Effect of malnutrition after acute stroke on clinical outcome. Stroke. 1996;27: $1028-1032$.

31. Gariballa SE, Parker SG, Taub N, Castleden CM. Influence of nutritional status on clinical outcome after acute stroke. Am J Clin Nutr. 1998; 68:275-281.

32. Crary MA, Carnaby-Mann GD, Miller L, Antonios N, Silliman S. Dysphagia and nutritional status at the time of hospital admission for ischemic stroke. J Stroke Cerebrovasc Dis. 2006;15:164-171.

33. Finestone HM, Foley NC, Woodbury MG, Greene-Finestone L. Quantifying fluid intake in dysphagic stroke patients: a preliminary comparison of oral and nonoral strategies. Arch Phys Med Rehabil. 2001;82:1744-1746.

34. Sellars C, Bowie L, Bagg J, et al. Risk factors for chest infection in acute stroke: a prospective cohort study. Stroke. 2007;38:2284-2291.

35. Masiero S, Pierobon R, Previato C, Gomiero E. Pneumonia in stroke patients with oropharyngeal dysphagia: a six-month follow-up study. Neurol Sci. 2008;29:139-145.
36. Pikus L, Levine MS, Yang YX, et al. Videofluoroscopic studies of swallowing dysfunction and the relative risk of pneumonia. Am J Roentgenol. 2003;180:1613-1616.

37. Ney DM, Weiss JM, Kind AJ, Robbins J. Senescent swallowing: impact, strategies, and interventions. Nutr Clin Pract. 2009;24:395-413.

38. Kidd D, Lawson J, Nesbitt R, MacMahon J. The natural history and clinical consequences of aspiration in acute stroke. QJM. 1995;88:409-413.

39. Horner J, Alberts MJ, Dawson DV, Cook GM. Swallowing in Alzheimer's disease. Alzheimer Dis Assoc Disord. 1994;8:177-19.

40. Morley JE. Nutrition in the elderly. Curr Opin Gastroenterol. 2002;18:240-245.

41. Claggett MS. Nutritional factors relevant to Alzheimer's disease. $J$ Am Diet Assoc. 1989;89:392-396.

42. Makowska I, Kloszewska I, Grabowska A, Szatkowska I, Rymarczyk K. Olfactory deficits in normal aging and Alzheimer's disease in the Polish elderly population. Arch Clin Neuropsychol. 2011;26:270-279.

43. Serby M, Larson P, Kalkstein D. The nature and course of olfactory deficits in Alzheimer's disease. Am J Psychiatry. 1991;148:357-360.

44. van der Maarel-Wierink CD, Vanobbergen JN, Bronkhorst EM, Schols JM, de Baat C. Risk factors for aspiration pneumonia in frail older people: a systematic literature review. J Am Med Dir Assoc. 2011;12:344-354.

45. Rofes L, Arreola V, Almirall J, et al. Diagnosis and management of oropharyngeal Dysphagia and its nutritional and respiratory complications in the elderly. Gastroenterol Res Practice. 2011. doi: $10.1155 / 2011 / 818979$.

46. Serra-Prat M, Palomera M, Gomez C, et al. Oropharyngeal dysphagia as a risk factor for malnutrition and lower respiratory tract infection in independently living older persons: a population-based prospective study. Age Ageing. 2012;41:376-381.

47. Brunnstrom HR, Englund EM. Cause of death in patients with dementia disorders. Eur J Neurol. 2009;16:488-492.

48. Zuliani G, Galvani M, Sioulis F, et al. Discharge diagnosis and comorbidity profile in hospitalized older patients with dementia. Int $J$ Geriatr Psychiatry. 2012;27:313-320.

49. Kaplan V, Angus DC, Griffin MF, Clermont G, Scott Watson R, Linde-Zwirble WT. Hospitalized community-acquired pneumonia in the elderly: age- and sex-related patterns of care and outcome in the United States. Am J Respir Crit Care Med. 2002;165:766-772.

50. Marik PE, Kaplan D. Aspiration pneumonia and dysphagia in the elderly. Chest. 2003;124:328-336.

51. Ewig S, Birkner N, Strauss R, et al. New perspectives on communityacquired pneumonia in 388406 patients. Results from a nationwide mandatory performance measurement programme in healthcare quality. Thorax. 2009;64:1062-1069.

52. Murphy S, Xu J, Kochanek KD. Deaths: Preliminary Data for 2010. National Vital Statistics Report: Center for Disease Control and Prevention; January 11, 2012. Available at: http://www.cdc.gov/nchs/ data/nvsr/nvsr60/nvsr60_04.pdf. Accessed April 11, 2012.

53. Almirall J, Bolibar I, Vidal J, et al. Epidemiology of communityacquired pneumonia in adults: a population-based study. Eur Respir J. 2000;15:757-763.

54. Loeb MB, Becker M, Eady A, Walker-Dilks C. Interventions to prevent aspiration pneumonia in older adults: a systematic review. JAm Geriatr Soc. 2003;51:1018-1022.

55. Cabre M, Serra-Prat M, Palomera E, Almirall J, Pallares R, Clave P. Prevalence and prognostic implications of dysphagia in elderly patients with pneumonia. Age Ageing. 2010;39:39-45.

56. Rasley A, Logemann JA, Kahrilas PJ, Rademaker AW, Pauloski BR, Dodds WJ. Prevention of barium aspiration during videofluoroscopic swallowing studies: value of change in posture. Am J Roentgenol. 1993;160:1005-1009.

57. Logemann JA, Gensler G, Robbins J, et al. A randomized study of three interventions for aspiration of thin liquids in patients with dementia or Parkinson's disease. J Speech Lang Hear Res. 2008;51: $173-183$. 
58. Shanahan TK, Logemann JA, Rademaker AW, Pauloski BR, Kahrilas PJ. Chin-down posture effect on aspiration in dysphagic patients. Arch Phys Med Rehabil. 1993;74:736-739.

59. Carnaby G, Hankey GJ, Pizzi J. Behavioural intervention for dysphagia in acute stroke: a randomised controlled trial. Lancet Neurol. 2006;5:31-37.

60. Johnsson F, Shaw D, Gabb M, Dent J, Cook I. Influence of gravity and body position on normal oropharyngeal swallowing. AM J Physiol. 1995;269:G653-G658.

61. Logemann JA, Rademaker AW, Pauloski BR, Kahrilas PJ. Effects of postural change on aspiration in head and neck surgical patients. Otolaryngol Head Neck Surg. 1994;110:222-227.

62. Logemann JA, Kahrilas PJ, Kobara M, Vakil NB. The benefit of head rotation on pharyngoesophageal dysphagia. Arch Phys Med Rehabil. 1989;70:767-771

63. Kahrilas PJ, Logemann JA, Krugler C, Flanagan E. Volitional augmentation of upper esophageal sphincter opening during swallowing. $A M$ J Physiol. 1991;260:G450-G456.

64. Hind JA, Nicosia MA, Roecker EB, Carnes ML, Robbins J. Comparison of effortful and noneffortful swallows in healthy middle-aged and older adults. Arch Phys Med Rehabil. 2001;82:1661-1665.

65. Huckabee ML, Butler SG, Barclay M, Jit S. Submental surface electromyographic measurement and pharyngeal pressures during normal and effortful swallowing. Arch Phys Med Rehabil. 2005;86:2144-2149.

66. Elmstahl S, Bulow M, Ekberg O, Petersson M, Tegner H. Treatment of dysphagia improves nutritional conditions in stroke patients. Dysphagia. 1999;14:61-66.

67. Neumann S, Bartolome G, Buchholz D, Prosiegel M. Swallowing therapy of neurologic patients: correlation of outcome with pretreatment variables and therapeutic methods. Dysphagia. 1995;10:1-5.

68. Carnaby-Mann GD, Crary MA. Adjunctive neuromuscular electrical stimulation for treatment-refractory dysphagia. Ann Otol Rhinol Laryngol. 2008;117:279-287.

69. Lazarus C, Logemann JA, Gibbons P. Effects of maneuvers on swallowing function in a dysphagic oral cancer patient. Head Neck. $1993 ; 15: 419-424$

70. Robbins JA, Nicosia M, Hind JA, Gill GD, Blanco R, Logemann JA. Defining physical properties of fluids for dysphagia evaluation and treatment. Perspectives on Swallowing and Swallowing Disorders. 2002;11:16-19.

71. Garcia JM, Chambers Et, Molander M. Thickened liquids: practice patterns of speech-language pathologists. Am J Speech Lang Pathol. 2005;14:4-13.

72. Kuhlemeier KV, Palmer JB, Rosenberg D. Effect of liquid bolus consistency and delivery method on aspiration and pharyngeal retention in dysphagia patients. Dysphagia. 2001;16:119-122.

73. Whelan K. Inadequate fluid intakes in dysphagic acute stroke. Clin Nutr. 2001;20:423-428

74. Robbins J, Gensler G, Hind J, et al. Comparison of 2 interventions for liquid aspiration on pneumonia incidence: a randomized trial. Ann Intern Med. 2008;148:509-518.

75. Panther K. Frazier Water Protocol: Safety Hydration and Quality of Life. Rockville, MD: American Speech, Language and Hearing Association; 2008

76. Groher ME, McKaig TN. Dysphagia and dietary levels in skilled nursing facilities. J Am Geriatr Soc. 1995;43:528-532.

77. Clayton J, editor. The National Dysphagia Diet: Standardization for Optimal Care. Chicago, IL: American Dietetic Association; 2002.

78. Wright L, Cotter D, Hickson M. The effectiveness of targeted feeding assistance to improve the nutritional intake of elderly dysphagic patients in hospital. J Hum Nutr Diet. 2008;21:555-562.

79. Wright L, Cotter D, Hickson M, Frost G. Comparison of energy and protein intakes of older people consuming a texture modified diet with a normal hospital diet. J Hum Nutr Diet. 2005;18:213-219.

80. Germain I, Dufresne T, Gray-Donald K. A novel dysphagia diet improves the nutrient intake of institutionalized elders. J Am Diet Assoc. 2006;106:1614-1623.
81. Langmore SE, Terpenning MS, Schork A, et al. Predictors of aspiration pneumonia: how important is dysphagia? Dysphagia. 1998;13:69-81.

82. Chandra RK. Nutrition and the immune system: an introduction. $A m$ J Clin Nutr. 1997;66:460S-463S.

83. Hengstermann S, Fischer A, Steinhagen-Thiessen E, Schulz RJ. Nutrition status and pressure ulcer: what we need for nutrition screening. J Parenter Enteral Nutr. 2007;31:288-294.

84. Wirth R, Volkert D, Bauer JM, et al. PEG tube placement in German geriatric wards - a retrospective data-base analysis. Z Gerontol Geriatr. 2007;40:21-30. German.

85. Cervo FA, Bryan L, Farber S. To PEG or not to PEG: a review of evidence for placing feeding tubes in advanced dementia and the decision-making process. Geriatrics. 2006;61:30-35.

86. Finucane TE, Christmas C, Travis K. Tube feeding in patients with advanced dementia: a review of the evidence. JAMA. 1999;282:1365-1370.

87. Grant MD, Rudberg MA, Brody JA. Gastrostomy placement and mortality among hospitalized Medicare beneficiaries. JAMA. 1998;279:1973-1976.

88. Roche V. Percutaneous endoscopic gastrostomy. Clinical care of PEG tubes in older adults. Geriatrics. 2003;58:22-26, 28-29.

89. Robbins J, Gangnon RE, Theis SM, Kays SA, Hewitt AL, Hind JA. The effects of lingual exercise on swallowing in older adults. $J \mathrm{Am}$ Geriatr Soc. 2005;53:1483-1489.

90. Carnaby-Mann G, Crary MA, Schmalfuss I, Amdur R. "Pharyngocise": Randomized Controlled Trial of Preventative Exercises to Maintain Muscle Structure and Swallowing Function During Head-and-Neck Chemoradiotherapy. Int J Radiat Oncol Biol Phys. 2011;83:210-219.

91. Carnaby-Mann GD, Crary MA. McNeill dysphagia therapy program: a case-control study. Arch Phys Med Rehabil. 2010;91:743-749.

92. Crary MA, Carnaby GD, Lagorio LA, Carvajal PJ. Functional and Physiological Outcomes from an Exercise-Based Dysphagia Therapy: A Pilot Investigation of the McNeill Dysphagia Therapy Program. Arch Phys Med Rehabil. 2012. [Epub ahead of print.]

93. Lazarus C, Logemann JA, Huang CF, Rademaker AW. Effects of two types of tongue strengthening exercises in young normals. Folia Phoniatr Logop. 2003;55:199-205.

94. Hagg M, Anniko M. Lip muscle training in stroke patients with dysphagia. Acta Otolaryngol. 2008;128:1027-1033.

95. Troche MS, Okun MS, Rosenbek JC, et al. Aspiration and swallowing in Parkinson disease and rehabilitation with EMST: a randomized trial. Neurology. 2010;75:1912-1919.

96. Shaker R, Kern M, Bardan E, et al. Augmentation of deglutitive upper esophageal sphincter opening in the elderly by exercise. AMJPhysiol. 1997;272:G1518-G1522.

97. Shaker R, Easterling C, Kern M, et al. Rehabilitation of swallowing by exercise in tube-fed patients with pharyngeal dysphagia secondary to abnormal UES opening. Gastroenterology. 2002;122:1314-1321.

98. Shaw GY, Sechtem PR, Searl J, Keller K, Rawi TA, Dowdy E. Transcutaneous neuromuscular electrical stimulation (VitalStim) curative therapy for severe dysphagia: myth or reality? Ann Otol Rhinol Laryngol. 2007;116:36-44.

99. Freed ML, Freed L, Chatburn RL, Christian M. Electrical stimulation for swallowing disorders caused by stroke. Respir Care. 2001;46:466-474.

100. Bulow M, Speyer R, Baijens L, Woisard V, Ekberg O. Neuromuscular electrical stimulation (NMES) in stroke patients with oral and pharyngeal dysfunction. Dysphagia. 2008;23:302-309.

101. Kiger M, Brown CS, Watkins L. Dysphagia management: an analysis of patient outcomes using VitalStim therapy compared to traditional swallow therapy. Dysphagia. 2006;21:243-253.

102. Crary MA. A direct intervention program for chronic neurogenic dysphagia secondary to brainstem stroke. Dysphagia. 1995;10:6-18.

103. Bryant M. Biofeedback in the treatment of a selected dysphagic patient. Dysphagia. 1991;6:140-144.

104. Crary MA, Carnaby Mann GD, Groher ME, Helseth E. Functional benefits of dysphagia therapy using adjunctive sEMG biofeedback. Dysphagia. 2004;19:160-164. 


\section{Publish your work in this journal}

Clinical Interventions in Aging is an international, peer-reviewed journal focusing on evidence-based reports on the value or lack thereof of treatments intended to prevent or delay the onset of maladaptive correlates of aging in human beings. This journal is indexed on PubMed Central, MedLine, the American Chemical Society's 'Chemical Abstracts Ser-

vice' (CAS), Scopus and the Elsevier Bibliographic databases. The manuscript management system is completely online and includes a very quick and fair peer-review system, which is all easy to use. Visit $\mathrm{http}: / /$ www.dovepress.com/testimonials.php to read real quotes from published authors.

Submit your manuscript here: http://www.dovepress.com/clinical-interventions-in-aging-journal 